\title{
Awareness and Potential Impacts of the Medicalization of Internet Gaming Disorder: Cross-sectional Survey Among Adolescents in China
}

\author{
Yanqiu $\mathrm{Yu}^{1}, \mathrm{PhD}$; Ji-Bin $\mathrm{Li}^{2}, \mathrm{PhD}$; Joseph T F Lau ${ }^{1}, \mathrm{PhD}$ \\ ${ }^{1}$ Center for Health Behaviours Research, Jockey Club School of Public Health and Primary Care, The Chinese University of Hong Kong, Hong Kong, \\ Hong Kong \\ ${ }^{2}$ Department of Clinical Research, Sun Yat-Sen University Cancer Center, State Key Laboratory of Oncology in South China, Collaborative Innovation \\ Center for Cancer Medicine, Guangzhou, China
}

\section{Corresponding Author:}

Joseph T F Lau, PhD

Center for Health Behaviours Research

Jockey Club School of Public Health and Primary Care

The Chinese University of Hong Kong

Prince Whales Hospital, Sha Tin

Hong Kong

Hong Kong

Phone: 85222528727

Email: jlau@cuhk.edu.hk

\section{Abstract}

Background: The Eleventh Revision of International Classification of Diseases (ICD-11) newly listed gaming disorder, including internet gaming disorder (IGD), as a disease. The level of awareness and potential positive and negative impacts of this medicalization among adolescents were unknown.

Objective: This study investigated the levels, associated factors, and potential positive and negative impacts of awareness of the medicalization of IGD among adolescents in China.

Methods: In a cross-sectional survey, 1343 middle school students in Guangzhou, China, self-administered an anonymous questionnaire in classrooms (October to December 2019). Three risk subgroups were identified: those who scored $\geq 5$ items in the Diagnostic and Statistical Manual of Mental Disorders, Fifth Edition checklist (IGD-S), those who self-perceived having IGD currently (IGD-PC), and those who self-perceived having IGD within 12 months (IGD-P12M).

Results: Of the internet gamers, $48.3 \%$ (460/952) were aware of the medicalization of IGD; they were more likely to belong to the IGD-P12M/IGD-S risk subgroups. Within the IGD-PC/IGD-P12M (but not IGD-S) risk subgroups, IGD medicalization awareness was positively associated with favorable outcomes (reduced internet gaming time in the past 12 months, seeking help from professionals if having IGD, and fewer maladaptive cognitions). After being briefed about the ICD-11 inclusion of IGD, $54.2 \%(516 / 952)$ and $32.8 \%$ (312/952) expressed that it would lead to the reduction of gaming time and help-seeking behaviors, respectively; however, $17.9 \%$ (170/952), 21.5\% (205/952), 15.9\% (151/952), and 14.5\% (138/952) perceived self-doubt for being diseased, stronger pressure from family members, negative emotional responses, and labeling effect, respectively. With a few exceptions, such perceived positive or negative impacts were stronger among the IGD-S, IGD-PC, and IGD-P12M risk subgroups.

Conclusions: The exploratory study shows that the medicalization of IGD may have benefits that need maximization and potentially harmful effects that need minimization. Future studies should test the efficacies of health promotion that increases IGD medicalization awareness.

(J Med Internet Res 2021;23(2):e22393) doi: 10.2196/22393

\section{KEYWORDS}

gaming disorder; ICD-11; high-risk subgroups; disease awareness; medicalization; internet gaming; awareness; impact; adolescent; young adult; China; game; disorder; ICD 


\section{Introduction}

Excessive internet gaming may cause a range of psychological and behavioral problems among adolescents $[1,2]$. Following the Diagnostic and Statistical Manual of Mental Disorders, Fifth Edition (DSM-5) definition announced in 2013, the World Health Organization (WHO) listed internet gaming disorder (IGD) as a subtype of gaming disorder in the International Classification of Diseases, Eleventh Revision (ICD-11) in 2018 [3] and formally endorsed the decision in May 2019 [4]. The classification of IGD as a disease reflects a medicalization process, which defines a health condition as a new disease that usually requires medical treatments [5]. Medicalization of diseases (eg, attention deficit hyperactivity disorder and social anxiety disorder) has been controversial [6-8]. The same is true for IGD. Supporters of the medicalization of IGD found similar neurological changes and addictive features among people with IGD and those with substance use disorders; they believed that medicalization would advance understandings of etiology, diagnosis, and treatment of IGD [9-18]. In contrast, the researchers who disagreed with this position were concerned about the absence of evidence-based treatment, overdiagnosis, and stigma toward heavily engaged internet gamers [19-21]. Medicalization's potential benefits include new opportunities for treatments, awareness for prevention, and reduction of stigma by regarding affected people as patients instead people who are weak or have character flaws $[5,9,10,17]$. It is important to understand whether adolescents know about the medicalization of IGD and how they respond to it.

We contend that awareness of the official ICD-11 inclusion of IGD (represented by the term IGD medicalization awareness in this study) may increase positive coping behaviors that may lead to prevention (ie, reduction of gaming time in the past 12 months) and treatment (ie, intention to seek help from mental health professionals if having IGD) among adolescent internet gamers, especially those at higher risk of IGD. Such contentions have not been tested, but the belief that internet addiction is an illness was positively associated with willingness to change pathological internet habits [22]. Conceptually, IGD medicalization awareness may increase perceived severity of problematic internet gaming. Both the fear appeal theory [23] and the health belief model [24] postulate that perceived severity of a health-related problem is associated with the adoption of related preventive behaviors. In this study, at-risk adolescent internet gamers included those whose DSM-5 scores objectively exceeded the cutoff point (IGD-S) and those who subjectively perceived that they were having IGD currently (IGD-PC) or going to have IGD in the next 12 months (IGD-P12M). In the cases of internet addiction, which was significantly correlated with IGD [25], only $28.2 \%$ of those who self-perceived having internet addiction intended to correct their addiction problems [26]. Furthermore, those who were at high risk of internet addiction were even less likely than others to change their internet habits [22]. Improvements are needed to improve motivation to reduce unhealthy gaming behaviors among adolescents at risk of IGD; health promotion to increase their IGD medicalization awareness is potentially useful.
IGD medicalization awareness may alter maladaptive cognitions related to internet gaming, which are known determinants of IGD [27,28]. A study comprehensively reviewed such maladaptive cognitions and proposed a 4-factor structure that was used to construct the Internet Gaming Cognition Scale $[27,29]$. It was modified into a 3-factor scale (ie, the Chinese version of Revised Internet Gaming Cognition Scale), which was validated among Chinese adolescents [30] and used in this study. Those with IGD medicalization awareness might restructure their maladaptive cognitions. For instance, they might perceive internet gaming as less rewarding if they knew that it was a disease. We thus contended a negative association between IGD medicalization awareness and maladaptive cognitions related to internet gaming within the aforementioned risk subgroups of internet gamers.

Despite potential benefits, the medicalization of IGD may in parallel cause unintended negative consequences [19]. It may trigger unfavorable emotional responses among internet gamers, especially those at higher risk of IGD. According to the common sense model, illness representation that includes both cognitive and emotional representations may generate emotional responses to the disease of concern in both diseased people [31] and laypeople [32]. Hence, internet gamers with IGD medicalization awareness (especially those with self-perceived IGD) may generate negative emotions related to problematic internet gaming (eg, anxiety, guilt, blame, and shame). Second, the medicalization of IGD may induce stigma and self-stigma related to internet gaming [20,33]. Globally, people with mental illnesses encounter stigma [34]. Although the ICD-11 definition specifies that heavily engaged internet gamers who have not exhibited serious problems due to internet gaming in the past 12 months are not IGD cases [3], the general public may be unable to distinguish between heavily engaged (but healthy) gamers and IGD cases [20]. Third, parental control of adolescents' internet gaming is common and often results in adolescent-parent conflicts [35]. When parents know about the medicalization of IGD, they may exert stronger pressure on adolescent internet gamers, enhancing their perceived stress [20]. Health workers hence need to alleviate potential negative consequences while pursuing the benefits of the medicalization of IGD. Perceptions of such positive and negative consequences of the medicalization of IGD have not been investigated.

Give such background, this study investigated (1) the prevalence of IGD medicalization awareness among adolescent internet gamers in mainland China; (2) adjusted associations between IGD medicalization awareness and reduction of internet gaming time (past 12 months), intention to seek help from mental health professionals if having IGD, and IGD-related maladaptive cognitions in 3 objectively and subjectively defined high-risk subgroups (IGD-S, IGD-PC, and IGD-P12M); (3) descriptions of perceived positive impacts (eg, reducing internet gaming time) and negative impacts (eg, labeling effect, emotional distress, and stronger pressure from family members) of the medicalization of IGD after participants were briefed about the inclusion of IGD into ICD-11 by the WHO; and (4) adjusted associations between the 3 types of IGD risk status and the aforementioned postbriefing perceived impacts. 


\section{Methods}

\section{Participants and Procedure}

An anonymous cross-sectional survey was conducted among grade 8 ( 8 years of formal education) students of 4 secondary schools selected by nonrandom sampling from October to December 2019 in Guangzhou, China. Under the supervision of trained and experienced field workers, the students self-administered the questionnaire in the classroom setting without the presence of teachers. Participants were briefed that the return of the questionnaire implied informed consent. No incentives were given. The data collection procedure was described elsewhere [30]. Of the 1343 completed questionnaires (response rate of 99.1\%), $1327(98.8 \%)$ were valid. Data obtained from the $962(72.5 \%)$ who had played internet games in the past 12 months were analyzed. The study was approved by the survey and behavioral research ethics committee of the Chinese University of Hong Kong (No. SBRE-18-430).

\section{Measures}

\section{Background Variables}

Information about sex (male or female), living arrangement with parents (whether living with both parents, either of the parents, or neither of the parents), single-parent family status, relative household income to their classmates (much higher, higher, moderate, lower, or much lower), and self-reported academic performance (below average, average, or above average) was collected.

\section{IGD Medicalization Awareness}

The item was: "Do you know that IGD has been defined as a disease by the WHO (yes/no responses)?"

\section{Objectively and Subjectively Defined IGD Risk Status}

IGD-S was objectively defined as the endorsement of 5 or more of the 9 items of the validated Chinese version of the DSM-5 checklist [36,37]; Cronbach alpha was .74 in this study.

IGD-PC was assessed subjectively: "Do you think that you currently have IGD (yes $=1$, no=0)?"

IGD-P12M was subjectively assessed: "Do you think that you are going to have IGD in the next 12 months (yes=1, no=0)?" Similar questions on self-perceived IGD status have been used in previous internet addiction studies [26,38].

\section{Maladaptive Cognitions Related to Internet Gaming}

The validated 15-item Chinese version of the Revised Internet Gaming Cognition Scale has an overall scale and 3 subscales ( $0=$ never to $4=$ always) [30]. The overall scale was used in this report (Cronbach alpha .93).

\section{Positive Coping Behavior/Intention}

The two items, answered yes $=1$ or no $=0$, were "Have you reduced internet gaming time in the past 12 months?" and "Would you seek help from mental health professionals if you have IGD?"

\section{Postbriefing Perceived Impacts of the Medicalization of IGD}

After being briefed that "The WHO approved the ICD-11 on May 25, 2019, which defined IGD as a disease. The member states of the WHO should develop their new treatment and prevention policies prior to January 1, 2022," participants rated a 6-item checklist (yes/no responses) on whether the new ICD-11 definition of IGD (medicalization) would impact them positively (ie, leading to participants' reduction of gaming time and seeking help from others) or negatively (ie, the news would lead to self-doubt being diseased, increase in parental pressure against playing internet games, labeling effect, and emotional distress due to playing internet games). These questions were asked at the last part of the questionnaire and thus could not affect the responses to the other questions.

\section{Statistical Analysis}

Logistic regression analyses were performed to investigate the associations involving binary outcomes, adjusted for background variables. Adjusted odds ratios and $95 \%$ confidence intervals were reported. Analysis of covariance was performed to compare between-group differences in the continuous dependent variables, adjusted for background variables. Cohen $d$ represented the effect sizes of the between-group differences. SPSS Statistics 21.0 (IBM Corporation) was used for data analysis; 2-tailed $P<.05$ and $.05<P<.10$ denoted statistical significance and marginal statistical significance, respectively.

\section{Results}

\section{Descriptive Statistics}

The results are presented in Table 1. About two-thirds (601/952, $63.1 \%$ ) of the internet gamers were males; $14.0 \%$ (133/952) did not live with both parents; $11 \%$ (105/952) came from single-parent families; 9.6\% (91/952) perceived lower/much lower household income relative to classmates; $27.3 \%$ (260/952) self-reported below-average academic performance. Of the internet gamers, $10.8 \%$ (103/952), 58.9\% (561/952), and 60.5\% (576/952) belonged to the IGD-S, IGD-PC, and IGD-P12M risk subgroups, respectively (see Table 1 ). Within such 3 subgroups, $50.5 \%$ (52/103), 62.6\% (351/561), and 65.5\% (377/576) self-reported that they had reduced internet gaming time in the past 12 months (69.1\% [658/952] among all gamers), and 31.1\% (32/103), 39.4\% (221/561), and 43.6\% (251/576) reported that they would seek help from mental health professionals if having IGD (44.9\% [427/952] among all gamers), respectively. 
Table 1. Descriptive statistics of the participants $(n=952)$.

\begin{tabular}{|c|c|}
\hline Characteristics & Value, $\mathrm{n}(\%)$ \\
\hline \multicolumn{2}{|l|}{ Background variables } \\
\hline \multicolumn{2}{|l|}{ Sex } \\
\hline Female & $351(36.9)$ \\
\hline Male & $601(63.1)$ \\
\hline \multicolumn{2}{|c|}{ Living arrangement with both parents } \\
\hline Yes & $818(85.9)$ \\
\hline No & $133(14.0)$ \\
\hline Missing data & $1(0.1)$ \\
\hline \multicolumn{2}{|c|}{ Single-parent family status } \\
\hline No & $844(88.7)$ \\
\hline Yes & $105(11.0)$ \\
\hline Missing data & $3(0.3)$ \\
\hline \multicolumn{2}{|c|}{ Household income relative to classmates } \\
\hline Higher/much higher & $282(29.6)$ \\
\hline Moderate & $570(59.9)$ \\
\hline Lower/much lower & $91(9.6)$ \\
\hline Missing data & $9(0.9)$ \\
\hline \multicolumn{2}{|c|}{ Self-reported academic performance } \\
\hline Above average & $198(20.8)$ \\
\hline Average & $492(51.7)$ \\
\hline Below average & $260(27.3)$ \\
\hline Missing data & $2(0.2)$ \\
\hline \multicolumn{2}{|c|}{ IGD ${ }^{\mathbf{a}}$ status (scored or perceived) } \\
\hline \multicolumn{2}{|l|}{ DSM $^{\mathbf{b}}{ }^{\mathrm{b}}$ scored IGD } \\
\hline No & $845(88.8)$ \\
\hline Yes & $103(10.8)$ \\
\hline Missing data & $4(0.4)$ \\
\hline \multicolumn{2}{|c|}{ Self-perceived having IGD currently } \\
\hline No & $385(40.4)$ \\
\hline Yes & $561(58.9)$ \\
\hline Missing data & $6(0.6)$ \\
\hline \multicolumn{2}{|c|}{ Going to have IGD in the next 12 months } \\
\hline No & $364(38.2)$ \\
\hline Yes & $576(60.5)$ \\
\hline Missing data & $12(1.3)$ \\
\hline \multicolumn{2}{|c|}{ Any of the above (scored or perceived IGD) } \\
\hline No & $259(27.2)$ \\
\hline Yes & $687(72.2)$ \\
\hline Missing data & $6(0.6)$ \\
\hline \multicolumn{2}{|l|}{ IGD medicalization awareness } \\
\hline No & $471(49.5)$ \\
\hline
\end{tabular}




\begin{tabular}{ll}
\hline Characteristics & Value, $\mathrm{n}(\%)$ \\
\hline Yes & $460(48.3)$ \\
Missing data & $21(2.2)$ \\
\hline
\end{tabular}

${ }^{\mathrm{a}}$ IGD: internet gaming disorder.

${ }^{\mathrm{b}}$ DSM-5: Diagnostic and Statistical Manual of Mental Disorders, Fifth Edition.

\section{Prevalence and Factors of IGD Medicalization Awareness}

Of the internet gamers, $48.3 \%$ (460/952) reported IGD medicalization awareness (see Table 1). No background variables were significantly associated with IGD medicalization awareness (see Table 2). Adjusted for all the studied background variables, the negative association between IGD-P12M status and IGD medicalization awareness (adjusted odds ratio [AOR] $0.76,95 \%$ CI $0.58-0.99$ ) was statistically significant; the negative association between IGD-S status and IGD medicalization awareness was of marginal statistical significance (AOR 0.65, 95\% CI 0.42-1.01; $P=.056$ ); that between IGD-PC status and IGD medicalization awareness was statistically nonsignificant (see Table 2). 
Table 2. Factors of internet gaming disorder medicalization awareness ${ }^{\mathrm{a}}(\mathrm{n}=952)$.

\begin{tabular}{|c|c|c|c|}
\hline \multirow[t]{2}{*}{ Characteristic } & \multicolumn{3}{|c|}{ IGD $^{\mathrm{b}}$ medicalization awareness } \\
\hline & $\mathrm{n}(\%)$ & $\mathrm{ORu}^{\mathrm{c}}(95 \% \mathrm{CI})$ & $\operatorname{AOR}^{\mathrm{d}}(95 \% \mathrm{CI})$ \\
\hline \multicolumn{4}{|l|}{ Background variables } \\
\hline \multicolumn{4}{|l|}{ Sex } \\
\hline Female & $176(50.6)$ & 1 & - \\
\hline Male & $284(48.7)$ & $0.93(0.71-1.21)$ & - \\
\hline \multicolumn{4}{|c|}{ Living arrangement with both parents } \\
\hline Yes & $404(50.3)$ & 1 & - \\
\hline No & $55(43.3)$ & $0.75(0.52-1.10)$ & - \\
\hline \multicolumn{4}{|c|}{ Single-parent family status } \\
\hline No & $413(50.0)$ & 1 & - \\
\hline Yes & $45(44.1)$ & $0.79(0.52-1.19)$ & - \\
\hline \multicolumn{4}{|c|}{ Household income relative to classmates } \\
\hline Higher/much higher & $145(52.7)$ & 1 & - \\
\hline Moderate & $268(47.9)$ & $0.83(0.62-1.10)$ & - \\
\hline Lower/much lower & $42(47.2)$ & $0.80(0.50-1.29)$ & - \\
\hline \multicolumn{4}{|c|}{ Self-reported academic performance } \\
\hline Above average & $101(52.1)$ & 1 & - \\
\hline average & $237(49.1)$ & $0.89(0.64-1.24)$ & - \\
\hline Below average & $121(48.0)$ & $0.85(0.59-1.24)$ & - \\
\hline \multicolumn{4}{|l|}{ IGD status } \\
\hline \multicolumn{4}{|l|}{ DSM-5 ${ }^{\mathrm{e}}$ scored IGD } \\
\hline No & $417(50.4)$ & 1 & 1 \\
\hline Yes & $40(40.0)$ & $0.66(0.43-1.00)$ & $0.65(0.42-1.01)$ \\
\hline \multicolumn{4}{|c|}{ Self-perceived having IGD currently } \\
\hline No & $203(53.1)$ & 1 & \\
\hline Yes & $255(46.6)$ & $0.77(0.59-1.00)$ & $0.80(0.61-1.05)$ \\
\hline \multicolumn{4}{|c|}{ Going to have IGD in the next 12 months } \\
\hline No & $196(54.4)$ & 1 & 1 \\
\hline Yes & $262(46.5)$ & $0.73(0.56-0.95)$ & $0.76(0.58-0.99)$ \\
\hline \multicolumn{4}{|c|}{ Any of the above (scored or perceived IGD) } \\
\hline No & $144(56.3)$ & 1 & 1 \\
\hline Yes & $314(46.7)$ & $0.68(0.51-0.91)$ & $0.71(0.53-0.96)$ \\
\hline
\end{tabular}

${ }^{\mathrm{a}}$ Missing data were excluded from the analyses.

${ }^{\mathrm{b}}$ IGD: internet gaming disorder.

${ }^{\mathrm{c}} \mathrm{ORu}$ : univariate odds ratio.

${ }^{\mathrm{d}}$ AOR: adjusted odds ratio.

${ }^{\mathrm{e}}$ DSM-5: Diagnostic and Statistical Manual of Mental Disorders, Fifth Edition.

\section{Associations Between IGD Medicalization Awareness and IGD and Potential Outcomes Within the Three High-Risk Subgroups}

In the IGD-PC and IGD-P12M subgroups, IGD medicalization awareness was significantly associated with the reduction in gaming time in the past 12 months (AOR 1.46 and AOR 1.45, respectively) and the intention to seek professional help if having IGD (AOR 1.80 and AOR 1.91, respectively). Such associations were, however, not statistically significant in the IGD-S subgroup. Among all internet gamers, IGD medicalization awareness was significantly associated with the intention to 
seek help from mental health professionals if having IGD (AOR $1.90,95 \%$ CI 1.45-2.47); the association between IGD medicalization awareness and reduction in internet gaming time in the past 12 months was of marginal statistical significance (AOR 1.32, 95\% CI 0.99-1.76; $P=.06$; see Figures 1 and 2). The adjusted analysis of covariance in Table 3 showed a similar pattern. The association between IGD medicalization awareness and maladaptive cognitions was not significant in the IGD-S subgroup but was statistically significant in the IGD-P12M subgroup (Cohen $d=0.24, P=.01$ ), marginally significant in the IGD-PC subgroup (Cohen $d=0.18 ; P=.07$ ), and significant among all internet gamers (Cohen $d=0.18, P=.02$ ).

Figure 1. Comparing percentages of participants self-reporting reduction in gaming time between those with and without internet gaming disorder medicalization awareness. IGD: internet gaming disorder; DSM-5: DSM-5: Diagnostic and Statistical Manual of Mental Disorders, Fifth Edition; AOR: adjusted odds ratio. $(\dagger: .05<P<.10 ; *: P<.05)$.

\section{IGD medicalization awareness $\quad$ Yes $\square$ No}

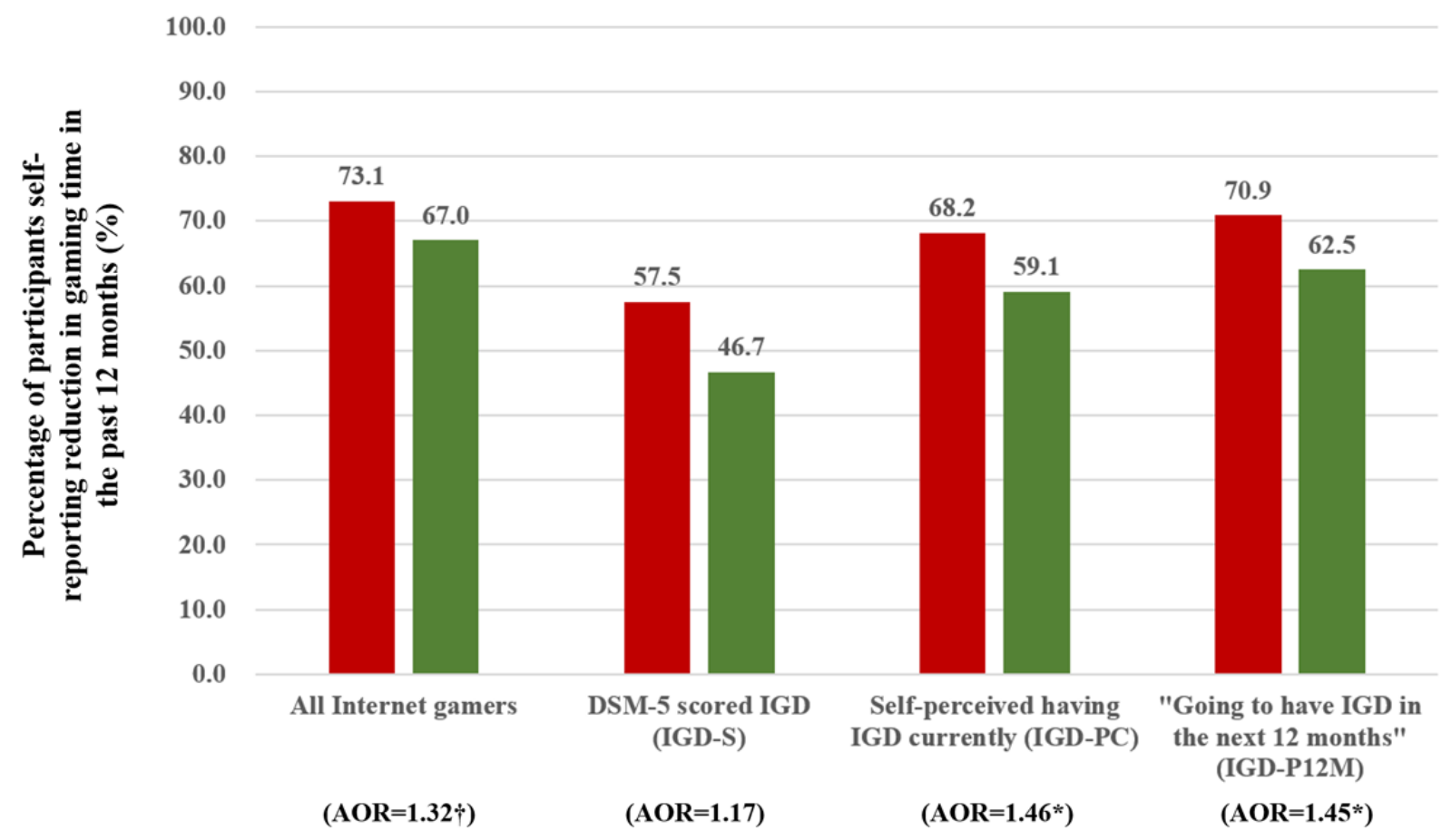


Figure 2. Comparing percentages of participants self-reporting intention to seek help from professionals between those with and without internet gaming disorder medicalization awareness. IGD: internet gaming disorder; DSM-5: DSM-5: Diagnostic and Statistical Manual of Mental Disorders, Fifth Edition; AOR: adjusted odds ratio. (**: $P<.01 ; * * *: P<.001)$.

\section{IGD medicalization awareness $\quad$ Yes $\square$ No}

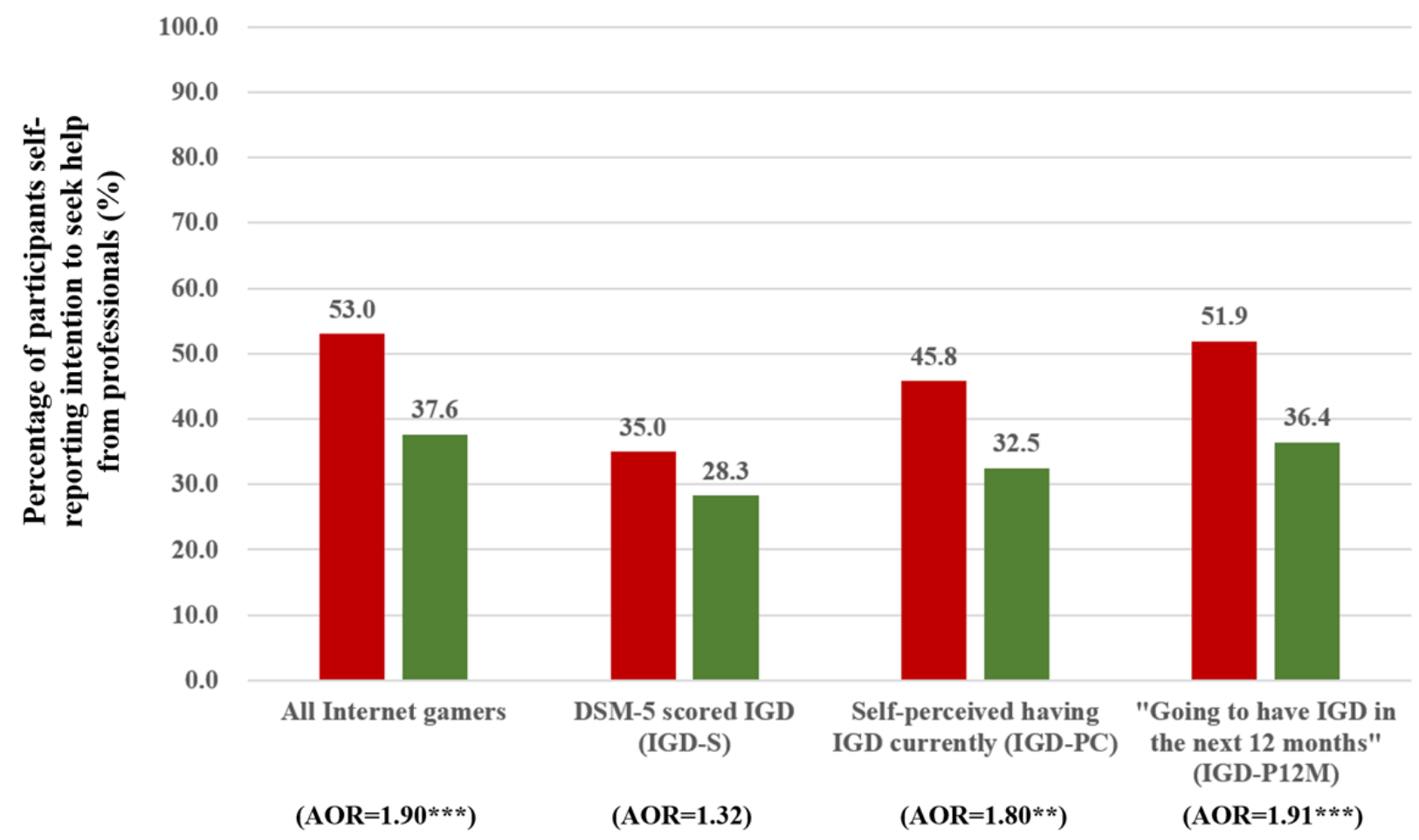

Table 3. Associations between internet gaming disorder medicalization awareness and preventive behavior/intention in the three high-risk subgroups ${ }^{\mathrm{a}}$.

\begin{tabular}{lllll}
\hline Overall maladaptive cognitions & \multicolumn{2}{l}{ IGD $^{\mathrm{b}}$ medicalization awareness } & & \\
& Yes, mean (SD) & No, mean (SD) & $P$ value & Cohen $d$ \\
\hline DSM-5 ${ }^{\mathrm{c}}$ scored IGD (n=100) & $32.5(14.1)$ & $33.2(12.0)$ & .82 & .09 \\
Self-perceived having IGD currently (n=582) & $23.6(11.2)$ & $25.5(11.4)$ & .07 & .18 \\
Going to have IGD in the next 12 months $(\mathrm{n}=576)$ & $22.3(11.0)$ & $25.0(11.5)$ & .01 & .24 \\
All internet gamers (n=952) & $20.2(11.1)$ & $22.2(11.8)$ & .02 & .18 \\
\hline
\end{tabular}

${ }^{\mathrm{a}}$ Missing data were excluded from the analyses.

${ }^{\mathrm{b}} \mathrm{IGD}$ : internet gaming disorder.

${ }^{\mathrm{e}}$ DSM-5: Diagnostic and Statistical Manual of Mental Disorders, Fifth Edition.

\section{Perceived Impacts of the Medicalization of IGD and Associations With Risk Status of IGD}

After being briefed about the new inclusion of IGD into the ICD-11 by the WHO (see Measurements), 54.2\% (516/952) of all the internet gamers indicated that this knowledge would make them spend less time on internet gaming, while $32.8 \%$ (312/952) indicated that it would drive them to seek help from others to deal with problems related to internet gaming (see Table 4). Besides, $17.9 \%$ (170/952), 21.5\% (205/952), $15.9 \%$ (151/952), and $14.5 \%$ (138/952) of the internet gamers, after being briefed about the medicalization, perceived that it would subject them to self-doubt for being diseased, stronger pressure from family members, development of negative emotions (eg, anxiety), and label as being sick, respectively (see Table 4).

IGD-PC and IGD-P12M status but not IGD-S status were positively associated with the two perceived positive impacts (reduction in internet gaming time and intention to seek help from others to deal with problems related to internet gaming) at significant or marginally significant levels. Moreover, IGD-S, IGD-PC, and IGD-P12M status were all positively and significantly associated with the 4 types of perceived negative impacts (AOR ranged from 1.69 to 3.23) except for one association (that between IGD-P12M status and labeling effect) of marginal significance (AOR 1.50, 95\% CI 1.00-2.26; $P=.05$; see Table 4). 
Table 4. Perceived impacts of the International Classification of Diseases, Eleventh Revision inclusion of internet gaming disorder among internet gamers $^{\mathrm{a}}(\mathrm{n}=952)$.

\begin{tabular}{|c|c|c|c|}
\hline Outcomes & $\mathrm{IV}^{\mathrm{b}}=\mathrm{yes}, \mathrm{n}(\%)$ & $\mathrm{IV}=\mathrm{no}, \mathrm{n}(\%)$ & $\operatorname{AOR}^{c}(95 \% \mathrm{CI})$ \\
\hline \multicolumn{4}{|l|}{ DSM-5 $^{\mathrm{d}}$ scored IGD $^{\mathrm{e}}$} \\
\hline Intend to reduce gaming time & $49(47.6)$ & $465(55.0)$ & $0.78(0.51-1.20)$ \\
\hline Intend to seek help from others & $34(33.0)$ & $277(32.8)$ & $0.99(0.63-1.57)$ \\
\hline Self-doubt for being diseased & $33(32.0)$ & $136(16.1)$ & $2.63(1.62-4.26)$ \\
\hline Stronger pressure from family members & $46(44.7)$ & $159(18.8)$ & $3.23(2.07-5.04)$ \\
\hline Being labeled as being sick & $27(26.2)$ & $111(13.1)$ & $2.23(1.35-3.70)$ \\
\hline Negative emotions & $33(32.0)$ & $117(13.8)$ & $2.96(1.83-4.79)$ \\
\hline \multicolumn{4}{|l|}{ Self-perceived having IGD currently } \\
\hline Intend to reduce gaming time & $321(57.2)$ & $193(50.1)$ & $1.34(1.02-1.76)$ \\
\hline Intend to seek help from others & $196(34.9)$ & $115(29.9)$ & $1.31(0.98-1.76)$ \\
\hline Self-doubt for being diseased & $125(22.3)$ & $45(11.7)$ & $1.92(1.31-2.83)$ \\
\hline Stronger pressure from family members & 149 (26.6) & $54(14.0)$ & $2.01(1.41-2.87)$ \\
\hline Being labeled as being sick & $101(18.0)$ & $36(9.4)$ & $1.94(1.27-2.96)$ \\
\hline Negative emotions & $106(18.9)$ & $45(11.7)$ & $1.69(1.14-2.50)$ \\
\hline \multicolumn{4}{|l|}{ Going to have IGD in the next 12 months } \\
\hline Intend to reduce gaming time & $327(56.8)$ & $184(50.5)$ & $1.28(0.98-1.68)$ \\
\hline Intend to seek help from others & $201(34.9)$ & $108(29.7)$ & $1.31(0.98-1.75)$ \\
\hline Self-doubt for being diseased & $128(22.2)$ & $41(11.3)$ & $2.10(1.42-3.12)$ \\
\hline Stronger pressure from family members & $157(27.3)$ & $45(12.4)$ & $2.61(1.80-3.79)$ \\
\hline Being labeled as being sick & $95(16.5)$ & $40(11.0)$ & $1.50(1.00-2.26)$ \\
\hline Negative emotions & $118(20.5)$ & $31(8.5)$ & $2.81(1.82-4.33)$ \\
\hline
\end{tabular}

${ }^{\mathrm{a}}$ Missing data were excluded from the analyses.

${ }^{\mathrm{b}} \mathrm{IV}$ : independent variable.

${ }^{\mathrm{c}}$ AOR: adjusted odds ratio.

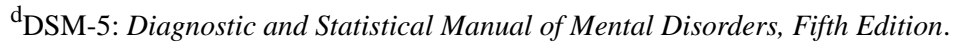

eIGD: internet gaming disorder.

Adjusted logistic regression models used those whose IGD risk status endorsing no as the reference groups (versus yes) and adjusted for background factors, including sex, living arrangement with both parents, single-parent family status, relative household income to their classmates, and self-reported academic performance.

\section{Discussion}

\section{Principal Findings}

In general, ICD-11 is highly influential [39]. The ICD-11 inclusion of IGD requires all nations to establish related prevention and treatment policies [9-11,13,14,16-18]. It is hence an expected driving force to reduce IGD worldwide. Health workers need to increase its benefits and reduce unintended negative consequences. It is essential to disseminate information about the new ICD-11 inclusion of IGD to adolescents and stakeholders (eg, parents, teachers, health workers, and social workers) as our data showed that the IGD medicalization awareness may reduce adolescent risky gaming behaviors and maladaptive cognitions related to internet gaming. It is equally important to understand adolescents' cognitive, behavioral, and emotional responses to the medicalization of IGD. This study filled out such knowledge gaps. There was no apparent social disparity in the IGD medicalization awareness as it was not associated with the studied background variables. Nonetheless, IGD medicalization awareness was lower in 2 high-risk subgroups (IGD-S $[.05<P<.10]$ and IGD-P12M $[P<.05]$ ); the promotion of the disease awareness should thus target at-risk adolescents.

It is encouraging that adolescents possessing IGD medicalization awareness were more likely than their counterparts to have (1) reduced gaming time in the last 12 months, (2) intention to seek help from professionals if having IGD, and (3) fewer IGD-related maladaptive cognitions. It is plausible that the knowledge about the medicalization of IGD may have enhanced adolescents' perceived severity of playing internet games excessively and motivations to take up preventive measures (eg, reducing gaming time and seeking help) according to the fear appeal theory [23] and the health belief model [24]. Such 
observed associations were triangulated by the encouraging finding that, similarly, many internet gamers indicated that they would reduce gaming time and seek help from others after being briefed about the medicalization of IGD. In the future, randomized controlled trials (RCTs) should be conducted to compare the efficacies of interventions providing adolescents IGD-related health promotion materials with and without additional information on the medicalization of IGD in fostering positive outcomes in terms of perceptions, mental distress, and behaviors related to IGD.

The associations between IGD medicalization awareness and the potential positive coping behavior/intention were more likely to be statistically significant within the 2 subjectively defined risk groups (IGD-PC and IGD-P12M) than within the objectively defined IGD group (IGD-S). The conceptual difference between diseases and illnesses is noteworthy. Diseases refer to objective clinical diagnoses, while illnesses refer to subjective experiences related to mental or physical symptoms [40,41]. The IGD-S subgroup was identified by the DSM-5 using a biomedical disease model, while the IGD-PC and IGD-P12M subgroups were subjectively evaluated and closer to the illness model. Understandably, those with illness perceptions (subjective beliefs of oneself being ill or going to be ill) were more prone to adopt positive corrective coping behaviors than those being objectively defined as IGD cases who might not feel ill. Besides, according to the health belief model [24], subjective perceptions of illness may be seen as a cue to action, which is a determinant of health-related behaviors (positive coping behaviors in our case).

Importantly, about one-fifth of the adolescent internet gamers showed concerns about side effects of the medicalization of IGD (eg, self-doubt about being diseased and worry about labeling effect). According to the common sense model [31], such problems may lead to mental health problems (eg, depression). Understandably, our data showed that the 3 at-risk subgroups were more likely than others to perceive the aforementioned negative consequences of the medicalization of IGD. To reduce such stigma, health education needs to clarify the distinction between heavily engaged internet gamers and disordered gamers.

\section{Limitations}

Although this study is possibly the first one to investigate awareness of the ICD-11 inclusion of IGD, it has some limitations. First, the findings of this study are exploratory in nature and need to be confirmed by longitudinal studies and RCTs. Second, the cross-sectional study design did not allow for the establishment of causality. Third, generalization of the results should be done with caution, as a limited number of schools were selected nonrandomly in one city in mainland China. Fourth, IGD medicalization awareness and potential responses to the medicalization (eg, reduction in gaming time) were assessed by self-reported single items that have not been validated. Fifth, social desirability bias might have inflated the levels of IGD medicalization awareness and positive coping behavior/intention. Sixth, the immediate postbriefing responses may not be reliable and may differ from actual behaviors.

\section{Conclusions}

Less than half the adolescent participants knew about the medicalization of IGD indicating there is room for improvement. The associations between IGD medicalization awareness and favorable coping behavior/intention/cognitions are encouraging. Dissemination of information about the inclusion of IGD into ICD-11 may induce adolescents to take up preventive and/or help-seeking behaviors. Such may be especially true within high-risk subgroups. Future RCTs are thus warranted to support the development of a simple, sustainable, and well-documented intervention that can be used to increase disease awareness of IGD among adolescents, possibly incorporating health promotion of healthy internet gaming. Through implementation research, such an evidence-based intervention can further be scaled up and used across countries. Furthermore, health workers need to minimize potential negative impacts of the medicalization (eg, avoidance of overpathologizing internet gamers). Research should also look at IGD medicalization awareness among other stakeholders (eg, parents, teachers, and social workers). This exploratory study is a starting point to understand the importance of potential effects of the medicalization of IGD.

\section{Acknowledgments}

This research was funded by National Natural Science Foundation of China (grant number 81373021). We would like to thank the participants for their contributions.

\section{Authors' Contributions}

YY and JTFL conceptualized the study. YY and JL designed the questionnaire. JL collected data. YY analyzed the data. YY and JTFL wrote the first draft of the manuscript. YY and JTFL revised and finalized the manuscript.

\section{Conflicts of Interest}

None declared.

\section{References}

1. Liau AK, Choo H, Li D, Gentile DA, Sim T, Khoo A. Pathological video-gaming among youth: a prospective study examining dynamic protective factors. Addiction Res Theory 2014 Dec 19;23(4):301-308. [doi: 10.3109/16066359.2014.987759] 
2. Brunborg GS, Mentzoni RA, Frøyland LR. Is video gaming, or video game addiction, associated with depression, academic achievement, heavy episodic drinking, or conduct problems? J Behav Addict 2014 Mar;3(1):27-32 [FREE Full text] [doi: 10.1556/JBA.3.2014.002] [Medline: 25215212]

3. International Classification of Diseases for Mortality and Morbidity Statistics, 11th Revision. World Health Organization. 2018. URL: https://icd.who.int/browse11/1-m/en [accessed 2021-02-02]

4. World Health Assembly Update: International Statistical Classification of Diseases and Related Health Problems (ICD-11). World Health Organization. 2019 May 25. URL: http://www.who.int/news-room/detail/ 25-05-2019-world-health-assembly-update [accessed 2021-04-30]

5. Conrad P, Bergey M. Medicalization: sociological and anthropological perspectives. In: Wright JD, editor. International Encyclopedia of the Social \& Behavioral Sciences (Second Edition). Philadelphia: Elsevier Science \& Technology; 2015:105-109.

6. Nigg JT. What Causes ADHD? Understanding What Goes Wrong and Why. New York: Guilford Press; 2006.

7. Conrad P, Slodden C. The medicalization of mental disorder. In: Handbook of the Sociology of Mental Health. London: Springer; 2013:61-73.

8. Sadler JZ, Jotterand F, Lee SC, Inrig S. Can medicalization be good? Situating medicalization within bioethics. Theor Med Bioeth 2009;30(6):411-425. [doi: 10.1007/s11017-009-9122-4] [Medline: 19997778]

9. Király O, Demetrovics Z. Inclusion of gaming disorder in ICD has more advantages than disadvantages. J Behav Addict 2017 Sep 01;6(3):280-284 [FREE Full text] [doi: 10.1556/2006.6.2017.046] [Medline: 28816495]

10. Billieux J, King DL, Higuchi S, Achab S, Bowden-Jones H, Hao W, et al. Functional impairment matters in the screening and diagnosis of gaming disorder. J Behav Addict 2017 Sep 01;6(3):285-289 [FREE Full text] [doi: 10.1556/2006.6.2017.036] [Medline: 28816514]

11. Müller KW, Wölfling K. Both sides of the story: addiction is not a pastime activity. J Behav Addict 2017 Jun 01;6(2):118-120 [FREE Full text] [doi: 10.1556/2006.6.2017.038] [Medline: 28662617]

12. King DL, Gaming Industry Response Consortium. Comment on the global gaming industry's statement on ICD-11 gaming disorder: a corporate strategy to disregard harm and deflect social responsibility? Addiction 2018 Nov;113(11):2145-2146. [doi: 10.1111/add.14388] [Medline: 30007117]

13. Higuchi S, Nakayama H, Mihara S, Maezono M, Kitayuguchi T, Hashimoto T. Inclusion of gaming disorder criteria in ICD-11: a clinical perspective in favor. J Behav Addict 2017 Sep 01;6(3):293-295 [FREE Full text] [doi:

10.1556/2006.6.2017.049] [Medline: 28816497]

14. Griffiths MD, Kuss DJ, Lopez-Fernandez O, Pontes HM. Problematic gaming exists and is an example of disordered gaming. J Behav Addict 2017 Sep 01;6(3):296-301 [FREE Full text] [doi: 10.1556/2006.6.2017.037] [Medline: 28816501]

15. Rumpf H, Achab S, Billieux J, Bowden-Jones H, Carragher N, Demetrovics Z, et al. Including gaming disorder in the ICD-11: the need to do so from a clinical and public health perspective. J Behav Addict 2018 Sep 01;7(3):556-561. [doi: 10.1556/2006.7.2018.59] [Medline: 30010410]

16. Shadloo B, Farnam R, Amin-Esmaeili M, Hamzehzadeh M, Rafiemanesh H, Jobehdar M, et al. Inclusion of gaming disorder in the diagnostic classifications and promotion of public health response. J Behav Addict 2017 Sep 01;6(3):310-312 [FREE Full text] [doi: 10.1556/2006.6.2017.048] [Medline: 28816499]

17. Lee S, Choo H, Lee HK. Balancing between prejudice and fact for Gaming Disorder: does the existence of alcohol use disorder stigmatize healthy drinkers or impede scientific research? J Behav Addict 2017 Sep 01;6(3):302-305 [FREE Full text] [doi: 10.1556/2006.6.2017.047] [Medline: 28816518]

18. Saunders JB, Hao W, Long J, King DL, Mann K, Fauth-Bühler M, et al. Gaming disorder: its delineation as an important condition for diagnosis, management, and prevention. J Behav Addict 2017 Sep 01;6(3):271-279 [FREE Full text] [doi: 10.1556/2006.6.2017.039] [Medline: 28816494]

19. van Rooij A, Ferguson C, Colder Carras M, Kardefelt-Winther D, Shi J, Aarseth E, et al. A weak scientific basis for gaming disorder: let us err on the side of caution. J Behav Addict 2018 Mar 01;7(1):1-9 [FREE Full text] [doi:

10.1556/2006.7.2018.19] [Medline: 29529886]

20. Aarseth E, Bean A, Boonen H, Colder Carras M, Coulson M, Das D, et al. Scholars' open debate paper on the World Health Organization ICD-11 Gaming Disorder proposal. J Behav Addict 2017 Sep 01;6(3):267-270 [FREE Full text] [doi: 10.1556/2006.5.2016.088] [Medline: 28033714]

21. Statement on the WHO ICD-11 list and the inclusion of gaming. European Games Developer Federation. 2018 Jun 15. URL: http://www.egdf.eu/wp-content/uploads/2018/06/Industry-Statement-on-18-June-WHO-ICD-11.pdf [accessed 2021-02-02]

22. Jiang Q, Leung L. Effects of individual differences, awareness-knowledge, and acceptance of internet addiction as a health risk on willingness to change internet habits. Soc Sci Comput Rev 2011 Feb 28;30(2):170-183. [doi: 10.1177/0894439311398440]

23. Peters GY, Ruiter RA, Kok G. Threatening communication: a critical re-analysis and a revised meta-analytic test of fear appeal theory. Health Psychol Rev 2013 May;7(Suppl 1):S8-S31 [FREE Full text] [doi: 10.1080/17437199.2012.703527] [Medline: 23772231] 
24. Janz NK, Becker MH. The Health Belief Model: a decade later. Health Educ Q 1984;11(1):1-47. [doi: 10.1177/109019818401100101] [Medline: 6392204]

25. Király O, Griffiths MD, Urbán R, Farkas J, Kökönyei G, Elekes Z, et al. Problematic internet use and problematic online gaming are not the same: findings from a large nationally representative adolescent sample. Cyberpsychol Behav Soc Netw 2014 Dec;17(12):749-754. [doi: 10.1089/cyber.2014.0475] [Medline: 25415659]

26. Lau JT, Wu AM, Cheng K, Tse VW, Lau MM, Yang X. Prevalence and factors of self-corrective intention among Hong Kong secondary school students who are self-assessed Internet addiction cases. Child Adolesc Ment Health 2018 Sep;23(3):155-163. [doi: 10.1111/camh.12219] [Medline: 32677295]

27. King DL, Delfabbro PH. The cognitive psychology of Internet gaming disorder. Clin Psychol Rev 2014 Jun;34(4):298-308 [FREE Full text] [doi: 10.1016/j.cpr.2014.03.006] [Medline: 24786896]

28. Billieux J, Potenza M, Maurage P, Brevers D, Brand M. Cognitive factors associated with gaming disorder. In: Verdejo-Garcia A, editor. Cognition and Addiction. Philadelphia: Elsevier; 2020:221-230.

29. King DL, Delfabbro PH. The cognitive psychopathology of internet gaming disorder in adolescence. J Abnorm Child Psychol 2016 Feb 15;44(8):1635-1645. [doi: 10.1007/s10802-016-0135-y] [Medline: 26875565]

30. Yu Y, Mo PK, Zhang J, Li J, Lau JT. Validation of the Chinese Version of the Revised Internet Gaming Cognition Scale among Adolescents in China: Maladaptive Cognitions as Potential Determinants of Internet Gaming Disorder. Int J Environ Res Public Health 2019 Dec 31;17(1):290 [FREE Full text] [doi: 10.3390/ijerph17010290] [Medline: 31906174 ]

31. Chan RC, Mak WW. Common sense model of mental illness: Understanding the impact of cognitive and emotional representations of mental illness on recovery through the mediation of self-stigma. Psychiatry Res 2016 Dec 30;246:16-24. [doi: 10.1016/j.psychres.2016.09.013] [Medline: 27644016]

32. Martin R, Rothrock N, Leventhal H. Common sense models of illness: implications for symptom perception and health-related behaviors. In: Suls J, Wallston KA, editors. Blackwell Series in Health Psychology and Behavioral Medicine. Social Psychological Foundations of Health and Illness. Hoboken: Blackwell Publishing; 2003:199-225.

33. Van Rooij AJ, Schoenmakers TM, Vermulst AA, Van Den Eijnden RJ, Van De Mheen D. Online video game addiction: identification of addicted adolescent gamers. Addiction 2010 Sep 15;106(1):205-212. [doi: 10.1111/j.1360-0443.2010.03104.x] [Medline: 20840209]

34. Rüsch N, Angermeyer M, Corrigan P. Mental illness stigma: concepts, consequences, and initiatives to reduce stigma. Eur Psychiatry 2005 Dec;20(8):529-539. [doi: 10.1016/j.eurpsy.2005.04.004] [Medline: 16171984]

35. Schneider LA, King DL, Delfabbro PH. Family factors in adolescent problematic Internet gaming: a systematic review. J Behav Addict 2017 Sep 01;6(3):321-333 [FREE Full text] [doi: 10.1556/2006.6.2017.035] [Medline: 28762279]

36. American Psychiatric Association. Diagnostic and Statistical Manual of Mental Disorders, Fifth Edition. Washington: American Psychiatric Association; 2013.

37. Ko C, Yen J, Chen S, Wang P, Chen C, Yen C. Evaluation of the diagnostic criteria of Internet gaming disorder in the DSM-5 among young adults in Taiwan. J Psychiatr Res 2014 Jun;53:103-110. [doi: 10.1016/j.jpsychires.2014.02.008] [Medline: 24581573]

38. Pontes HM, Szabo A, Griffiths MD. The impact of Internet-based specific activities on the perceptions of Internet addiction, quality of life, and excessive usage: a cross-sectional study. Addict Behav Rep 2015 Jun;1:19-25 [FREE Full text] [doi: 10.1016/j.abrep.2015.03.002] [Medline: 29531976]

39. ICD-11 Implementation or Transition Guide. Geneva: World Health Organization; 2019. URL: https://dxrevisionwatch. files.wordpress.com/2019/06/icd-11-implementation-or-transition-guide_v105-1.pdf [accessed 2021-02-02]

40. Last J, International Epidemiological Association. A Dictionary of Epidemiology. New York: Oxford University Press; 1995.

41. Wikman A, Marklund S, Alexanderson K. Illness, disease, and sickness absence: an empirical test of differences between concepts of ill health. J Epidemiol Community Health 2005 Jun;59(6):450-454 [FREE Full text] [doi: 10.1136/jech.2004.025346] [Medline: 15911638]

\section{Abbreviations}

AOR: adjusted odds ratio

DSM-5: Diagnostic and Statistical Manual of Mental Disorders, Fifth Edition

ICD-11: International Classification of Diseases, Eleventh Revision

IGD: internet gaming disorder

IGD-S: Scored IGD status

IGD-P12M: Perceived future IGD status in the next 12 months

IGD-PC: Perceived current IGD status

RCT: randomized controlled trial

WHO: World Health Organization 
Edited by G Eysenbach; submitted 10.07.20; peer-reviewed by A Dominguez-Rodriguez, S Stefanov; comments to author 01.10.20; revised version received 12.11.20; accepted 17.01.21; published 24.02.21

Please cite as:

Yu Y, Li JB, Lau JTF

Awareness and Potential Impacts of the Medicalization of Internet Gaming Disorder: Cross-sectional Survey Among Adolescents in China

J Med Internet Res 2021;23(2):e22393

URL: https://www.jmir.org/2021/2/e22393

doi: $\underline{10.2196 / 22393}$

PMID: 33625362

(C) Yanqiu Yu, Ji-Bin Li, Joseph T F Lau. Originally published in the Journal of Medical Internet Research (http://www.jmir.org), 24.02.2021. This is an open-access article distributed under the terms of the Creative Commons Attribution License (https://creativecommons.org/licenses/by/4.0/), which permits unrestricted use, distribution, and reproduction in any medium, provided the original work, first published in the Journal of Medical Internet Research, is properly cited. The complete bibliographic information, a link to the original publication on http://www.jmir.org/, as well as this copyright and license information must be included. 